Check for updates

Cite this: RSC Adv., 2017, 7, 19385

Received 19th January 2017

Accepted 27th March 2017

DOI: $10.1039 / \mathrm{c} 7 \mathrm{ra00830a}$

rsc.li/rsc-advances

\title{
Fast microwave-assisted conjugation of magnetic nanoparticles with carboxylates of biological interest $\uparrow$
}

\author{
M. S. Gutiérrez, M. N. Piña and J. Morey iD *
}

A new technique of surface modification of nanoparticles ( $\mathrm{Fe}_{3} \mathrm{O}_{4}-\mathrm{NP}$ ) with carboxylates of biological interest has been developed with a microwave-assisted heating method. This two-step technique reduces the reaction time to $15 \mathrm{~min}$ (for each step) and increases the number of substituents to 2300 molecules compared to traditional methods with a maximum of 440 molecules.

\section{Introduction}

In the search of new functional materials, it is important to consider magnetic nanoparticles $\left(\mathrm{Fe}_{3} \mathrm{O}_{4}-\mathrm{NP}\right)$ as a valuable support for biological applications, such as magnetic fluid hyperthermia applications, magnetic resonance imaging (MRI), immunoassays, labelling for cells catalysis, and targeted drug delivery.

In most cases $\mathrm{Fe}_{3} \mathrm{O}_{4}$-NP are synthesized in the presence of surfactants, like oleic acid, to prevent aggregation among them. In order to improve the stability of the nanoparticles, the ligand molecules on the surface can be exchanged by others that can possibly provide new properties or functionality to the particles, with the incoming ligand molecule binding more strongly to the inorganic nanoparticle surface. Nanoparticles with better stability are those with strong covalent interactions with their ligands. ${ }^{1-4}$

An excellent proposal as a bifunctional linker is 3-aminopropyltriethoxysilane (APTES) which is able to make covalent binding at both sites, the first with inorganic nanoparticle surface and the second with organic molecules via amidation., It is important to conjugate the largest number of molecules on $\mathrm{Fe}_{3} \mathrm{O}_{4}$-NP surface to improve efficiency of materials. For that reason we propose a fast method assisted by microwave heating. Also, in this work we tested different carboxylates, namely, folic acid (FA), methotrexate (MTX), pemetrexed (PMX), raltitrexed (RTX), glutathione (GSH) and dimercaptosuccinic acid (DMSA) (Scheme 1), with biological applications like drugs for treatment and prevention of cancer and heavy metals chelation..$^{2,5,7-10}$

In previous works, ${ }^{5-7,11-13}$ conjugation of $\mathrm{Fe}_{3} \mathrm{O}_{4}$-NP with APTES and similar linkers takes long reaction times and poor

Department of Chemistry, University of the Balearic Islands, Cra. de Valldemossa $\mathrm{Km}$. 7.5, 07122 Palma de Mallorca, Balearic Islands, Spain.E-mail: jeroni.morey@uib.es; Fax: +34971 173 426; Tel: +34971172690

$\dagger$ Electronic supplementary information (ESI) available. See DOI: 10.1039/c7ra00830a yields which does not allow $\mathrm{Fe}_{3} \mathrm{O}_{4}$-NP to be functionalized beyond 300-500 molecules per each nanoparticle (1.2 molecules per $\left.\mathrm{nm}^{2}\right) .{ }^{3,5}$ In general microwave processes are energy and time

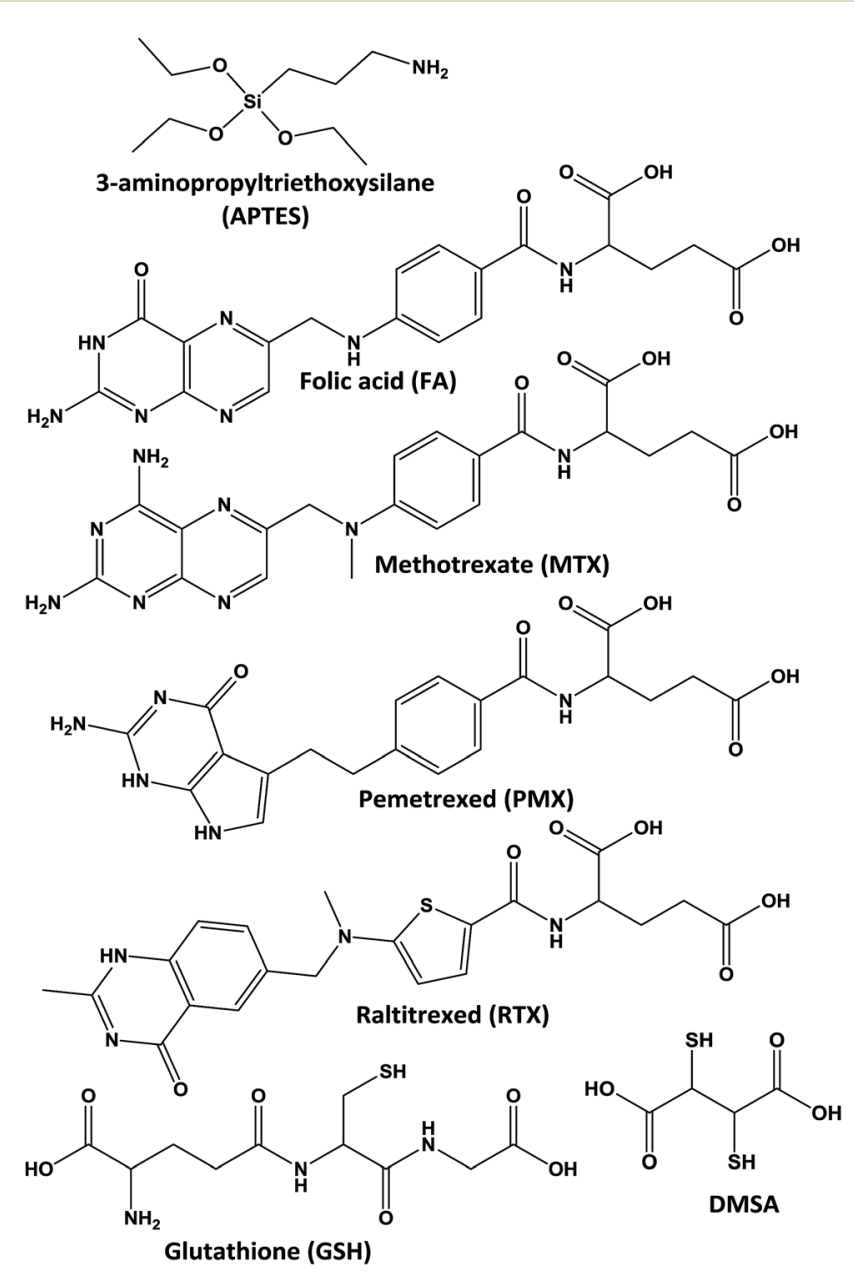

Scheme 1 Linker and biological molecules used in this work to functionalize $\mathrm{Fe}_{3} \mathrm{O}_{4}-\mathrm{NP}$. 
saving, reduce thermal gradient effects, thus leading to better results, and also can provide cleaner reactions.

In the present research, we exploit the potential of the microwave technique, on one hand, to improve the coupling processes with carboxylates on the $\mathrm{Fe}_{3} \mathrm{O}_{4}$-NP surface and, on the other hand, to reduce the reaction time from hours to few minutes. ${ }^{\mathbf{1 4}}$ The amount of molecules loaded on magnetic nanoparticles was estimated by UV-Vis and TGA, and the results have been compared with those reported in the literature.

\section{Results and discussion}

\section{Synthesis of $\mathrm{Fe}_{3} \mathrm{O}_{4}$-NP via thermal decomposition}

Among different kinds of methodologies to synthesize $\mathrm{Fe}_{3} \mathrm{O}_{4^{-}}$ $\mathrm{NP},{ }^{15}$ the one that controls the NP size is the best option to get monodisperse $\mathrm{Fe}_{3} \mathrm{O}_{4}$-NP with 3 to $20 \mathrm{~nm}$ in diameter. The uniform shape and size distribution of $\mathrm{Fe}_{3} \mathrm{O}_{4}$-NP was analyzed by transmission electron microscopy (TEM) and showed an iron oxide core of about $8 \mathrm{~nm}$ in diameter on average. Fig. 1 shows FTIR with typical $-\mathrm{CH}_{2}-\mathrm{CH}_{2}-$ absorption band at $2920 \mathrm{~cm}^{-1}$ and $-\mathrm{CH}_{2}-\mathrm{CH}_{3}$ at $2850 \mathrm{~cm}^{-1}, \mathrm{C}=\mathrm{O}$ bond at $1590 \mathrm{~cm}^{-1}$, and $\mathrm{Fe}-$ $\mathrm{O}$ bond for magnetic nanoparticles at $630 \mathrm{~cm}^{-1}$.

\section{Functionalization of $\mathrm{Fe}_{3} \mathrm{O}_{4}$-NP-APTES via microwave and characterization}

In the search of better hybrid nanomaterials, the key is a correct functionalization of the particle surface. As the first step to improve traditional methods it is important to choose the appropriate solvent for microwave heating, to increase temperatures and decrease reaction times. For instance, in previous works, ${ }^{5}$ the reaction is undertaken in toluene anhydride, sonicating for 4 hours at $60{ }^{\circ} \mathrm{C}$ and finally washed with EtOH. According to the bibliography, we used the same reagents proportions and tested different organic solvents to enhance the insertion of APTES on $\mathrm{Fe}_{3} \mathrm{O}_{4}$-NP surface. Water, EtOH and $\mathrm{MeOH}$ were not used because they can hydrolyze APTES. The final product was magnetically separated and washed with EtOH to remove rests of APTES in the reaction medium. From

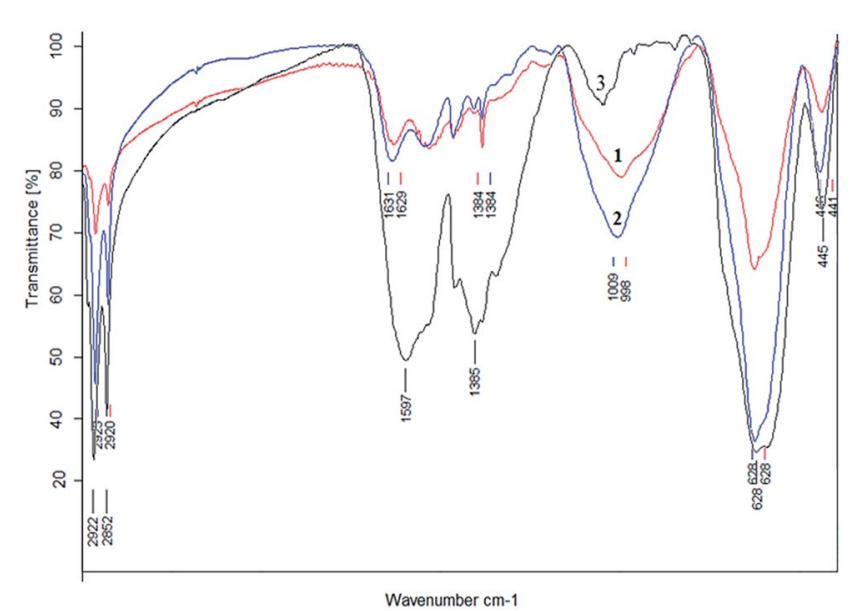

Fig. 1 FTIR of $\mathrm{Fe}_{3} \mathrm{O}_{4}$-NP-APTES (1) traditional reaction, (2) microwave reaction and (3) $\mathrm{Fe}_{3} \mathrm{O}_{4}$-NP-oleic acid. the results of these reactions gathered in Table 1 it can be inferred that toluene is the best option. Accordingly, we determined the best conditions for microwave heating at $120{ }^{\circ} \mathrm{C}, 2$ bar, and 15 minutes $(P=400 \mathrm{~W})$ with toluene as solvent. Other solvents (acetone, acetonitrile) reached higher pressures under the same reaction conditions, but were not good candidates because they are not able to promote the exchange of substituents. In other cases, solvents with higher boiling points than toluene make difficult to clean the final product. APTES coating was confirmed by FTIR (Fig. 1) with typical Si-O bond at 1000 $\mathrm{cm}^{-1}$. There are also bands at 628 and $446 \mathrm{~cm}^{-1}$ which are typical for Fe-O. By inspecting the FTIR results, obtained from $1 \mathrm{mg}$ of dried product and $100 \mathrm{mg}$ of $\mathrm{KBr}$ (in both cases), a high functionalization for the microwave-assisted process is observed.

\section{Amidation on $\mathrm{Fe}_{3} \mathrm{O}_{4}$-NP surface and characterization}

In order to study fast covalent bonding of antifolates and other organic molecules, we prepared six different hybrid nanoparticles: $\mathrm{Fe}_{3} \mathrm{O}_{4}$-NP-APTES-FA, $\mathrm{Fe}_{3} \mathrm{O}_{4}$-NP-APTES-MTX, $\mathrm{Fe}_{3} \mathrm{O}_{4^{-}}$ NP-APTES-PMX, $\mathrm{Fe}_{3} \mathrm{O}_{4}$-NP-APTES-RTX, $\mathrm{Fe}_{3} \mathrm{O}_{4}$-NP-APTES-GSH, and $\mathrm{Fe}_{3} \mathrm{O}_{4}$-NP-APTES-DMSA. Analogously to the previous chapter, the microwave treatment and the classical heating mode for the $\mathrm{Fe}_{3} \mathrm{O}_{4}$-NP functionalization were compared. The free $-\mathrm{NH}_{2}$ groups present on APTES react with antifolates via activation of the carboxylic groups by the carbodiimide $/ N$ hydroxysuccinimide method using the microwave technique. Traditional processes ${ }^{7,16}$ perform amidation reaction on the $\mathrm{Fe}_{3} \mathrm{O}_{4}$-NP surface at $37^{\circ} \mathrm{C}$ overnight with DMSO as solvent. Here we propose a fast method, adapted from the literature, ${ }^{17-19} \mathrm{using}$ microwave heating $(P=400 \mathrm{~W})$ and $\mathrm{MeOH} / \mathrm{H}_{2} \mathrm{O}$ as solvent at $120^{\circ} \mathrm{C}$. All experiments reached 4 bar of pressure in 15 minutes of reaction. Size distribution of different $\mathrm{Fe}_{3} \mathrm{O}_{4}$ - $\mathrm{NP}$ was analyzed by TEM (Fig. 2) showing particles of $8 \mathrm{~nm}$ in average. For a better view, TEM complete microphotographs are shown in the ESI (Fig. S12 and S13†).

FTIR shows the correct functionalization of $\mathrm{Fe}_{3} \mathrm{O}_{4}-\mathrm{NP}$ in all cases. The presence of $\mathrm{C}=\mathrm{O}$ stretching bands at $1630 \mathrm{~cm}^{-1}$ are typical of monosubstituted amide groups, confirmed with the presence of an $\mathrm{N}-\mathrm{H}$ band at $1550 \mathrm{~cm}^{-1}$; $\mathrm{Si}-\mathrm{O}$ bond is still present at $1000 \mathrm{~cm}^{-1}$, and $\mathrm{Fe}-\mathrm{O}$ bond at $630 \mathrm{~cm}^{-1}$ (Fig. 3). The general procedure of modification via microwave is shown in

Table 1 List of results of different solvents used for the $\mathrm{Fe}_{3} \mathrm{O}_{4}-\mathrm{NP}$ APTES functionalization

\begin{tabular}{llll}
\hline Solvent & $\begin{array}{l}\text { Boiling point } \\
\left({ }^{\circ} \mathrm{C}\right)\end{array}$ & Pressure (bar) & Results \\
\hline Acetone & 56.0 & 4 & No reaction \\
Acetonitrile & 82.0 & 3 & No reaction \\
$\mathrm{CH}_{2} \mathrm{Cl}_{2}$ & 39.6 & 7 & Precipitate \\
$\mathrm{DMF}$ & 153.0 & 0 & No reaction \\
DMSO & 189.0 & 0 & No reaction \\
Hexane & 68.0 & 2 & Precipitate \\
Toluene & 110.6 & 2 & Precipitate \\
Xylene & 137.0 & 1 & Precipitate
\end{tabular}




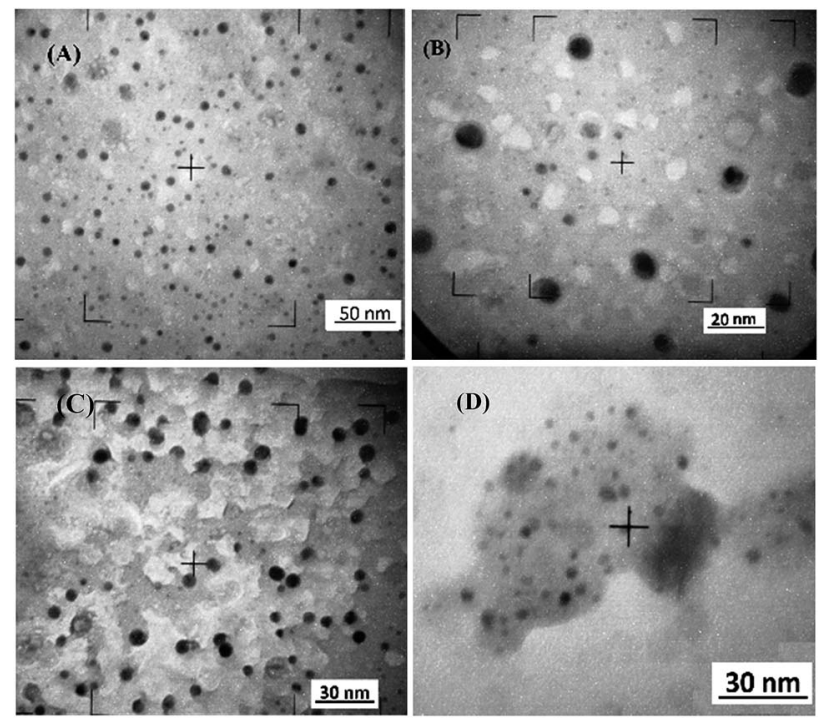

Fig. 2 TEM microphotographs (A) $\mathrm{Fe}_{3} \mathrm{O}_{4}-\mathrm{NP}$-oleic acid. (B) $\mathrm{Fe}_{3} \mathrm{O}_{4}$ NP-APTES-. (C) $\mathrm{Fe}_{3} \mathrm{O}_{4}$-NP-APTES-GSH. (D) $\mathrm{Fe}_{3} \mathrm{O}_{4}$-NP-APTES-FA.

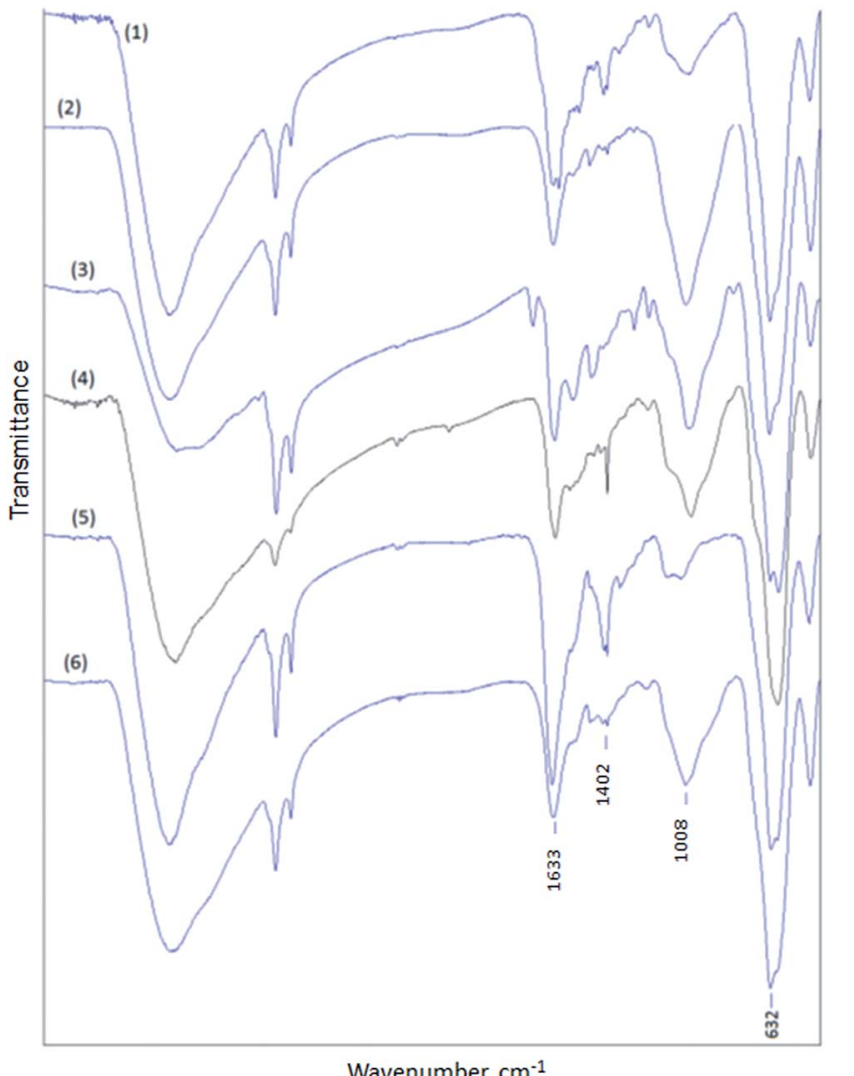

Fig. 3 FTIR of $\mathrm{Fe}_{3} \mathrm{O}_{4}$-NP-APTES- (1) FA, (2) MTX, (3) PMX, (4) RTX, (5) GSH and (6) DMSA.

Scheme 2. The FTIR spectra performed for the free carboxylates are shown in the ESI (Fig. S1-S5†). In addition, the MS spectrum data are included in the Experimental section. These results confirm that the reaction was successfully performed.

\section{Determination of number of molecules on $\mathrm{Fe}_{3} \mathrm{O}_{4}-\mathrm{NP}$ surface}

It is important to have a precise control on the number and orientation of the immobilized molecules on nanoparticles because carboxylates coordination occurs via APTES free amine groups. In previous works, the concentration of APTES and carboxylates (MTX, PMX and RTX) covalently bounded on the $\mathrm{Fe}_{3} \mathrm{O}_{4}$-NP surface was estimated by the standard addition method by ${ }^{1} \mathrm{H}$-NMR and UV-VIS through the residues of the reaction applying the following equations:

$$
N=\frac{\pi}{6} \frac{D^{3} \rho}{\mathrm{mw}} \frac{1}{N}=\frac{\text { nanoparticles }}{\mathrm{mol} \mathrm{Fe}_{3} \mathrm{O}_{4}}
$$

where $1 / N$ refers to the number of $\mathrm{Fe}_{3} \mathrm{O}_{4}$-NP for each mol of $\mathrm{Fe}_{3} \mathrm{O}_{4} . D$ is the average diameter of $\mathrm{Fe}_{3} \mathrm{O}_{4}-\mathrm{NP}$ in $\mathrm{cm}$ (provided by TEM microphotographs), $\rho$ is $\mathrm{Fe}_{3} \mathrm{O}_{4}$ density $\left(5.196 \mathrm{~g} \mathrm{~cm}^{-3}\right)$ and $\mathrm{mw}$ is the molecular weight of $\mathrm{Fe}_{3} \mathrm{O}_{4}\left(231.53 \mathrm{~g} \mathrm{~mol}{ }^{-1}\right) \cdot{ }^{20}$ In order to improve and clarify the number of substituents, we chose TGA method to determine the conjugation rate by measuring the mass loss due to decomposition. Experiments were performed with a constant heating rate of $10^{\circ} \mathrm{C} \mathrm{min}^{-1}$ from room temperature $\left(25{ }^{\circ} \mathrm{C}\right)$ to $1000{ }^{\circ} \mathrm{C}$. The mass lost from $25{ }^{\circ} \mathrm{C}$ to $100{ }^{\circ} \mathrm{C}$ has not been taken into account in the calculations, because it corresponds to the loss of water and/or solvents that may contain the sample. The TGA curves show weight loss in both cases (Fig. 4). Using weight loss percentage values it is possible to quantify the number of molecules on $\mathrm{Fe}_{3} \mathrm{O}_{4}$-NP surface by applying previous equations. Our main results together with bibliographic data are summarized in Table 2.

The microwave-assisted functionalization and conjugation reported herein clearly shows a substantial improvement in most cases over other reported methods. For APTES conjugation, the density of molecules per $\mathrm{nm}^{3}(\xi)$ is doubled, thereby increasing the number of $-\mathrm{NH}_{2}$ groups available for further amidation. The same result is observed for the amidation process, which suggest two ideas; first, a low number of linkers results in a low concentration of carboxylates and, second, the reaction conditions for the amidation reaction reported in the literature produces very low reaction yields if compared with our results.

\section{Experimental section}

\section{Materials}

All commercially available reagents: oleylamine $(\geq 98 \%$ (primary amine)), oleic acid ( $\geq 99 \%$ (GC)), dibenzyl ether (purum, $\geq 98.0 \%$ (GC)), were supplied by Sigma-Aldrich. All the solvents were purchased from Scharlau (all solvents have superior to $98 \%$ purity). Ferric acetylacetonate (purum, $\geq 97.0 \%$ (RT)) was supplied by Fluka.

\section{Instrumentation}

Infrared (IR) was obtained on Bruker Tensor 27 instrument in solid state. Ultraviolet-visible (UV-Vis) was obtained on a Shimadzu UV-2401PC Spectrometer. Matrix-assisted laser desorption/ionization mass spectra (MALDI), was recorded with a Autoflex III MALDI TOF/TOF mass spectrometer provided with 

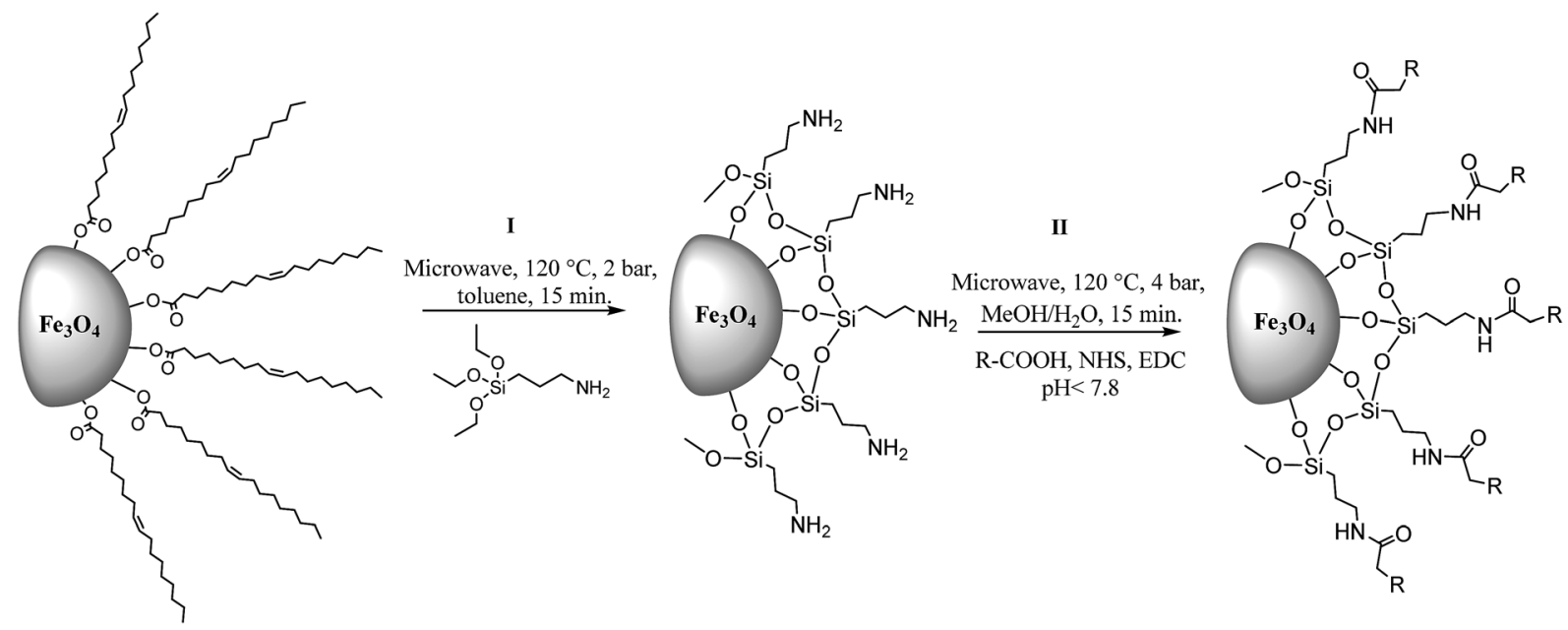

Scheme 2 General procedure for $\mathrm{Fe}_{3} \mathrm{O}_{4}-\mathrm{NP}$ functionalization.

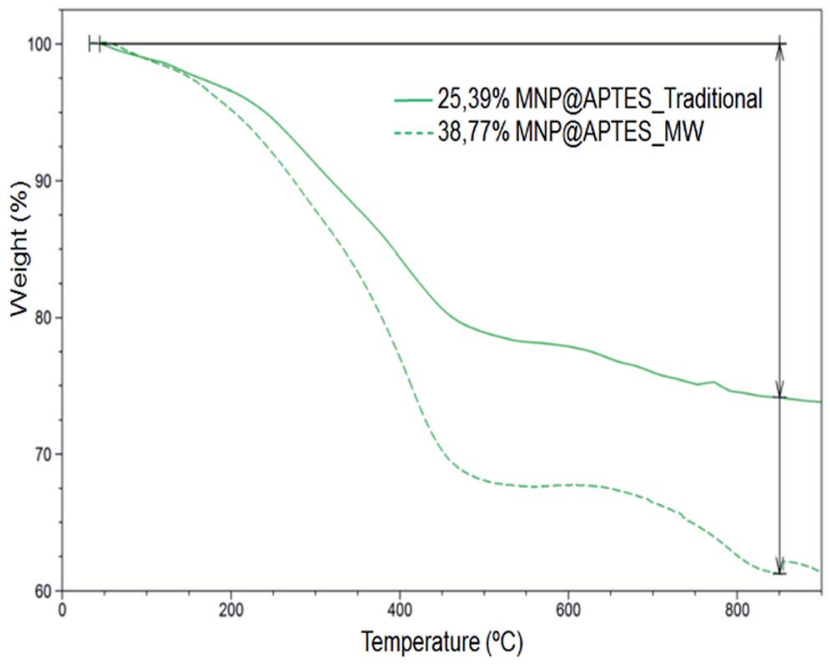

Fig. 4 Thermogravimetric analysis for $\mathrm{Fe}_{3} \mathrm{O}_{4}$-NP-APTES.

an Smart beam Laser at $200 \mathrm{~Hz}$. Functionalization of $\mathrm{Fe}_{3} \mathrm{O}_{4}-\mathrm{NP}$ was performed on a Biotage Initiator Classic Microwave Synthesizer at $400 \mathrm{~W}$. TGA were performed on a SDT Q-600 instrument.

\section{Methods}

FTIR. For IR experiments, $100 \mathrm{mg}$ of anhydrous $\mathrm{KBr}$ were mixed with $1 \mathrm{mg}$ of each product (perfectly dried) and grounded in a mortar to make a tablet.

TGA. To perform the analysis, all the samples were perfectly dried with vacuum before weighing them.

TEM. The samples of nanoparticles were dissolved in ethanol to support them in grids. The micrographics were prepared in ultrathin carbon type A400 mesh (pkg/50) grids.

Mass analysis. All the samples of nanoparticles were prepared with $1 \mathrm{mg}$ of dried sample, digested for 1 hour with $\mathrm{HCl}(37 \%)$ filtered, vacuum dried and redissolved in $1 \mathrm{~mL}$ of Milli-Q water.

\section{Synthesis and characterization of $\mathrm{Fe}_{3} \mathrm{O}_{4}-\mathrm{NP}$}

For the synthesis of $\mathrm{Fe}_{3} \mathrm{O}_{4}$ nanoparticles, an adapted procedure of S. Sun et al. $^{21}$ was used. Fe(acac) $)_{3}(2 \mathrm{mmol})$, oleic acid (6 $\mathrm{mmol})$, oleylamine $(6 \mathrm{mmol})$ were mixed into $20 \mathrm{~mL}$ of dibenzyl ether and magnetically stirred under a flow of argon. The solution was heated firstly at $200{ }^{\circ} \mathrm{C}$ for $1 \mathrm{~h}$ and then at $300{ }^{\circ} \mathrm{C}$ for $2 \mathrm{~h}$ with vigorous magnetic stirring with reflux under $\mathrm{Ar}$ atmosphere.

Table 2 Thermogravimetric and particle size values of $\mathrm{Fe}_{3} \mathrm{O}_{4}-\mathrm{NP}$ functionalized by the two methods

\begin{tabular}{|c|c|c|c|c|c|c|}
\hline & Technique & Analysis method & $\begin{array}{l}\theta \\
(\mathrm{nm})\end{array}$ & $\begin{array}{l}\text { Weight loss } \\
(\%)\end{array}$ & Molecules $/ \mathrm{Fe}_{3} \mathrm{O}_{4}-\mathrm{NP}$ & $\begin{array}{l}\xi \\
\left(\text { molecules per } \mathrm{nm}^{3}\right)\end{array}$ \\
\hline $\mathrm{Fe}_{3} \mathrm{O}_{4}$-NP-oleic acid & - & TGA & 8 & 42.01 & 2142 & 4.18 \\
\hline $\mathrm{Fe}_{3} \mathrm{O}_{4}$-NP-APTES & Traditional & TGA & 8 & 25.39 & 1284 & 2.51 \\
\hline $\mathrm{Fe}_{3} \mathrm{O}_{4}$-NP-APTES & Microwave & TGA & 8 & 38.72 & 2380 & 4.65 \\
\hline $\mathrm{Fe}_{3} \mathrm{O}_{4}$-NP-APTES ${ }^{a}$ & Traditional & ${ }^{31} \mathrm{P}$ NMR titration & 10 & - & 1200 & 1.20 \\
\hline $\mathrm{Fe}_{3} \mathrm{O}_{4}$-NP-APTES-MTX ${ }^{b}$ & Traditional & Standard addition & 10 & - & 419 & 0.42 \\
\hline $\mathrm{Fe}_{3} \mathrm{O}_{4}$-NP-APTES-MTX & Microwave & TGA & 8 & 52.69 & 2046 & 4.00 \\
\hline $\mathrm{Fe}_{3} \mathrm{O}_{4}$-NP-APTES-RTX ${ }^{c}$ & Traditional & Standard addition & 6 & - & 363 & 1.70 \\
\hline $\mathrm{Fe}_{3} \mathrm{O}_{4}$-NPAPTES-RTX & Traditional & TGA & 8 & 9.39 & 1142 & 0.54 \\
\hline $\mathrm{Fe}_{3} \mathrm{O}_{4}$-NPAPTES-RTX & Microwave & TGA & 8 & 38.55 & 1142 & 2.23 \\
\hline $\mathrm{Fe}_{3} \mathrm{O}_{4}$-NP-APTES-PMX ${ }^{c}$ & Traditional & Standard addition & 6 & - & 164 & 0.85 \\
\hline $\mathrm{Fe}_{3} \mathrm{O}_{4}$-NP-APTES-PMX & Microwave & Standard addition & 8 & - & 2113 & 4.13 \\
\hline
\end{tabular}

${ }^{a} \mathrm{~F}$. Benyettou et $a l^{3}{ }^{b} \mathrm{~N}$. Kohler et $a l^{7{ }^{c}} \mathrm{~K}$. López et $a l .{ }^{5}$ 
The solution was cooled at room temperature. Nanoparticles were precipitated by adding $25 \mathrm{~mL}$ of ethanol to the mixture. The precipitated was collected by centrifugation at $8000 \mathrm{rpm}$, washed with ethanol $(3 \mathrm{~mL} \times 15 \mathrm{~mL})$ and redispersed in $25 \mathrm{~mL}$ of hexane or acetonitrile (depending on the type of reaction that will take place later), to a final concentration of $0.025 \mathrm{mmol} \mathrm{mL}^{-1}$. FTIR (KBr): 3406, 2921, 2851, 1591, 1384, and $632 \mathrm{~cm}^{-1}$.

\section{Functionalization of $\mathrm{Fe}_{3} \mathrm{O}_{4}$-NP with APTES via microwave}

For APTES functionalization procedure has been adapted from Zhang et al. ${ }^{7,11}$ to microwave reactor. $0.1 \mathrm{~mL}$ of APTES was added to $1.7 \mathrm{~mL}$ of $\mathrm{Fe}_{3} \mathrm{O}_{4}$-NP-oleic acid colloidal suspension in a $5 \mathrm{~mL}$ flask with $3 \mathrm{~mL}$ of toluene and hermetically closed. The mixture was heated in the microwave reactor under magnetic stirring for $15 \mathrm{~min}$ at $120^{\circ} \mathrm{C}$ and 2 bar. $\mathrm{Fe}_{3} \mathrm{O}_{4}$-NP-APTES was magnetically precipitated and washed with $\mathrm{EtOH}(3 \times 5 \mathrm{~mL})$ and finally dispersed in $\mathrm{MeOH}$ for the next step. FTIR (KBr): 3384, 2920, 2651, 1629, 1384, 998 and $628 \mathrm{~cm}^{-1}$.

\section{Covalent conjugation via microwave: amidation reaction}

Amidation reaction procedure has been adapted from bibliography ${ }^{3,11,22,23}$ to microwave reactor. $0.025 \mathrm{mmol}$ of carboxylic acid $(\mathrm{FA}=11.04 \mathrm{mg}$, MTX $=11.36 \mathrm{mg}$, PMX = 10.69, $\mathrm{RTX}=$ $11.46 \mathrm{mg}, \mathrm{GSH}=7.68 \mathrm{mg}$, DMSA $=4.56 \mathrm{mg}$ ) is dissolved in distillated water. Moreover $34.8 \mathrm{mg}$ of EDC and $5.81 \mathrm{mg}$ of NHS was dissolved in $1 \mathrm{~mL}$ of distillated water, both dissolutions were mixed and $\mathrm{pH}$ was adjusted to 8 , finally $\mathrm{Fe}_{3} \mathrm{O}_{4}$-NP-APTES dispersed in $\mathrm{MeOH}$ is added to the mixture, hermetically closed and heated in the microwave reactor under magnetic stirring for $15 \mathrm{~min}$ at $120{ }^{\circ} \mathrm{C}$ and 2 bar. $\mathrm{Fe}_{3} \mathrm{O}_{4}$-NP-APTES-R was magnetically precipitated and washed with distillated $\mathrm{H}_{2} \mathrm{O}(3 \times$ $5 \mathrm{~mL}$ ). To preserve the product, $\mathrm{Fe}_{3} \mathrm{O}_{4}$-NP-APTES-R was dissolved on a $\mathrm{NH}_{4} \mathrm{OH}$ solution of $1 \%$.

FTIR (KBr): $\mathbf{F e}_{3} \mathbf{O}_{4}$-NP-APTES-FA. 3385, 2921, 2852, 1631, 1385, 993, 630, 590 and $445 \mathrm{~cm}^{-1}$. $\mathrm{Fe}_{3} \mathrm{O}_{4}$-NP-APTES-MTX: 3385 , 2921, 2852, 1625, 1555, 1446, 1384, 1199, 990, 590 and 442 $\mathrm{cm}^{-1}$. $\mathrm{Fe}_{3} \mathrm{O}_{4}$-NP-APTES-PMX: 3380, 2921, 2851, 1729, 1628, 1546, 1459, 1260, 1011, 631 and $591 \mathrm{~cm}^{-1}$. $\mathrm{Fe}_{3} \mathrm{O}_{4}$-NP-APTESRTX: 3385, 2912, 2854, 1626, 1558, 1448, 1384, 997, 596 and $444 \mathrm{~cm}^{-1} . \mathrm{Fe}_{3} \mathrm{O}_{4}$-NP-APTES-GHS: 3419, 2922, 2852, 1635, 1556, 1385, 998, 59 and $443 \mathrm{~cm}^{-1}$. $\mathrm{Fe}_{3} \mathrm{O}_{4}$-NP-APTES-DMSA: 3385, 2921, 2852, 1631, 1385, 993, 630, 590 and $445 \mathrm{~cm}^{-1}$.

MALDI. APTES-FA: found $m / z 624.844[\mathrm{M}],\left[\mathrm{C}_{25} \mathrm{H}_{33} \mathrm{~N}_{8} \mathrm{NaO}_{8} \mathrm{Si}\right]$ requires 624.209. APTES-MTX $(+)$ : found $m / z 701.501[\mathrm{M}]^{+}$, $\left[\mathrm{C}_{25} \mathrm{H}_{33} \mathrm{FeN}_{9} \mathrm{Na}_{2} \mathrm{O}_{7} \mathrm{Si}^{+}\right]$requires 701.502. APTES-PMX: found $\mathrm{m} / \mathrm{z}$ 475.342 [M] $]^{+},\left[\mathrm{C}_{20} \mathrm{H}_{25} \mathrm{~N}_{6} \mathrm{Na}_{2} \mathrm{O}_{5}{ }^{+}\right]$requires 475.168. APTES-RTX: found $m / z \quad 440.950[\mathrm{M}]^{-},\left[\mathrm{C}_{21} \mathrm{H}_{21} \mathrm{~N}_{4} \mathrm{O}_{5} \mathrm{~S}^{-}\right]$requires 441.123 . APTES-GSH: found $m / z 510.880[\mathrm{M}],\left[\mathrm{C}_{15} \mathrm{H}_{31} \mathrm{FeN}_{4} \mathrm{O}_{8} \mathrm{SSi}\right]$ requires 511.098. APTES-DMSA found $m / z 383.967$ [M], $\left[\mathrm{C}_{9} \mathrm{H}_{18} \mathrm{FeNO}_{6} \mathrm{~S}_{2} \mathrm{Si}\right]$ requires 383.968 .

\section{Conclusions}

In summary, we have developed a new and fast microwaveassisted technique for the functionalization of $\mathrm{Fe}_{3} \mathrm{O}_{4}$-NP with a high yield of conjugation and short reaction times, and demonstrated that the grafting rate was increased by using the microwave technique. A significant difference was encountered when comparing the nanoparticles functionalized via microwave with those obtained in a traditional way.

The number of molecules on $\mathrm{Fe}_{3} \mathrm{O}_{4}$-NP surface has been determined by thermogravimetric analysis and compared with standard addition method, the former showing better results. All the carboxylates used in this work showed similar results for the amidation reaction.

\section{Acknowledgements}

This work was financially supported by Ministerio de Economía y Competitividad ref. CTQ2014-57393-C2-1-P M. Susana Gutiérrez acknowledges her Ph.D. scholarship from CONACyT (Consejo Nacional de Ciencia y Tecnología de México).

\section{Notes and references}

1 Y.-J. Liang, Y. Zhang, Z. Guo, J. Xie, T. Bai, J. Zou and N. Gu, Chem.-Eur. J., 2016, 22, 1-10.

2 Y. Pan, M. J. C. Long, X. Li, J. Shi, L. Hedstrom and B. Xu, Chem. Sci., 2011, 2, 945-948.

3 F. Benyettou, E. Guenin, Y. Lalatonne and L. Motte, Nanotechnology, 2011, 22, 55102.

4 R. A. Sperling and W. J. Parak, Philos. Trans. R. Soc., A, 2010, 368, 1333-1383.

5 K. A. López, M. N. Piña, R. Alemany, O. Vögler, F. Barceló and J. Morey, RSC Adv., 2014, 4, 19196.

6 M. Ma, Y. Zhang and W. Yu, Colloids Surf., A, 2003, 212, 219-226.

7 N. Kohler, C. Sun, J. Wang and M. Zhang, Langmuir, 2005, 21, 8858-8864.

8 C. Chen, J. Ke, X. E. Zhou, W. Yi, J. S. Brunzelle, J. Li, E.-L. Yong, H. E. Xu and K. Melcher, Nature, 2013, 500, 486-489.

9 H.-H. S. Chow, I. A. Hakim, D. R. Vining, J. A. Crowell, M. E. Tome, J. Ranger-Moore, C. A. Cordova, D. M. Mikhael, M. M. Briehl and D. S. Alberts, Cancer Epidemiol., Biomarkers Prev., 2007, 16, 1662-1666.

10 P.-J. Chen, S.-H. Hu, C.-S. Hsiao, Y.-Y. Chen, D.-M. Liu and S.-Y. Chen, J. Mater. Chem., 2011, 21, 2535.

11 K. A. López, M. N. Piña and J. Morey, Sens. Actuators, B, 2013, 181, 267-273.

12 A. M. Demin, V. P. Krasnov and V. N. Charushin, Mendeleev Commun., 2013, 23, 14-16.

13 M. De, P. S. Ghosh and V. M. Rotello, Adv. Mater., 2008, 20, 4225-4241.

14 R. Cecilia, U. Kunz and T. Turek, Chem. Eng. Process., 2007, 46, 870-881.

15 R. G. Chaudhuri and S. Paria, Chem. Rev., 2012, 112, 23732433.

16 C. J. Zhou, S. H. Wang, Y. Zhou, P. F. Rong, Z. Z. Chen, J. Y. Liu and J. Da Zhou, Trans. Nonferrous Met. Soc. China, 2013, 23, 2079-2084.

17 M. Milošević, I. Šterbal, U. Feguš, J. Baškovč, B. Prek, U. Grošelj, B. Stanovnik and J. Svete, J. Heterocycl. Chem., 2015, 52, 556-561. 
18 N.-S. Cho, H.-J. Jeon and D.-U. Heo, J. Korean Chem. Soc., 2012, 56, 658-660.

19 P. Sharma, N. Kaur, P. Sharma, R. Sirohi and D. Kishore, Bull. Chem. Soc. Ethiop., 2013, 27, 301-307.

20 L. Wang, J. Luo, Q. Fan, M. Suzuki, I. S. Suzuki, M. H. Engelhard, Y. Lin, N. Kim, J. Q. Wang and C.-J. Zhong, J. Phys. Chem. B, 2005, 109, 21593-21601.
21 S. Sun and H. Zeng, J. Am. Chem. Soc., 2002, 124, 8204-8205. 22 P. Lidström, J. Tierney, B. Wathey and J. Westman, Tetrahedron, 2001, 57, 9225-9283.

23 N. Nakajima and Y. Ikada, Bioconjugate Chem., 1995, 6, 123130. 